\title{
How to Defend a Normative Ethical Theory
}

\author{
Keith Burgess-Jackson \\ The University of Texas at Arlington, Arlington, TX, USA \\ Email:kbj@uta.edu,kbj4@att.net
}

How to cite this paper: Burgess-Jackson, K. (2021). How to Defend a Normative Ethical Theory. Open Journal of Philosophy, 11, 229-248.

https://doi.org/10.4236/ojpp.2021.112018

Received: March 21, 2021

Accepted: May 9, 2021

Published: May 12, 2021

Copyright (c) 2021 by author(s) and Scientific Research Publishing Inc. This work is licensed under the Creative Commons Attribution International License (CC BY 4.0).

http://creativecommons.org/licenses/by/4.0/

\begin{abstract}
This article is a work of metaethics; it is on, but not in, normative ethics. My aim is to explain how one goes about defending a normative ethical theory. Specifically, it is to explain how one goes about providing (what I call) "a complete defense" of a normative ethical theory. A complete defense has five components, which I call "underpinning," "undermining," "countermining," "attacking," and "repelling." I explain and illustrate each component, using the normative ethical theory of egoism as an example. I then discuss three important distinctions. The first is between ideal complete defenses and non-ideal (or real-world) complete defenses. The second is between complete defenses (whether ideal or non-ideal) and incomplete (or partial) defenses. The third is between successful defenses (whether complete or incomplete) and unsuccessful defenses.
\end{abstract}

\section{Keywords}

Ethics, Metaethics, Normative Ethics, Theory, Argumentation, Ethical Egoism

\section{Introduction}

There is more than one theory about how we should act.... What's more, these different theories are genuine rivals, they are not merely alternative ways of saying the very same thing. They disagree-not always, to be sure, but sometimes-about precisely which acts are morally permitted, required, or forbidden. Since they disagree, they cannot all be right: we must choose between them. But what is to guide our choice? On what grounds are we to accept or reject a normative theory? How can a moral claim be defended? (Kagan, 1998: p. 11 [italics in original]).

Shelly Kagan's questions presuppose answers to several others. For example: What is a theory? What types of theory are there? Do different types of theory 
have a common (or single) purpose? If so, what is it? How does one go about defending a theory? Are there different types of defense for different types of theory? Are there different types of defense for a given type of theory? If so, what are they?

The purpose of this article is to explain how one goes about defending a normative ethical theory. During the course of this explanation, I answer all of the questions just posed. Specifically, I explain how to provide (what I call) "a complete defense" of a normative ethical theory. I shall use as my example the theory known as "ethical egoism" (hereafter "egoism"). ${ }^{1}$ This theory may not have as many adherents as other theories (such as utilitarianism, Kantianism, and contractarianism), but it has an ancient and respectable lineage. Most contemporary textbooks on ethics discuss it, if only to find fault with it. Scholarly monographs and articles continue to be written about it, some glowingly and some vituperatively. (One philosopher goes so far as to call the theory-and, by implication, those who subscribe to it-"pernicious" and "wicked" [Rachels, 1974: pp. 297, 298].) Almost nobody is indifferent to it.

\section{What Is a Theory?}

[A] moral theory involves the attempt to explain the nature of morality. More precisely, that part of a moral theory concerned with right and wrong action-its theory of right conduct-attempts to explain the nature of right and wrong action by locating those features of actions, persons, and situations that make an act right or wrong (Timmons, 2002: p. 246 [italics in original]).

Let us begin at the beginning, by answering the questions posed in the first paragraph of the article. A theory, in simple terms, is an explanation (or account) of why things are as they are. ${ }^{2}$ The things in question may be of any sort. A physical theory is an account of physical objects as such-of why they possess the properties and relations they do. A biological theory is an account of living organisms as such-of how and why they develop as they do, behave as they do, and possess the properties they do. An economic theory is an account of economic phenomena, such as wages, prices, unemployment, and currency inflation. A psychological theory is an account of psychological phenomena, such as belief, intention, motivation, learning, and emotion. A normative ethical theory

\footnotetext{
${ }^{1}$ Ethical egoism is not to be confused with either psychological egoism or rational egoism. Ethical egoism (see Burgess-Jackson, 2013b) is a normative ethical theory. Psychological egoism (see Burgess-Jackson, 2013c) is a testable scientific theory about human motivation. The consensus among philosophers is that, depending on how it is interpreted, psychological egoism is either false or trivially true. Rational egoism is a normative theory of rationality. It says that it is rational for an agent to perform an act if and only if that act maximizes the agent's utility (or expectable utility) in the long run.

${ }^{2}$ The fourth definition of the word "theory" in the Oxford English Dictionary (1971) is as follows: "A scheme or system of ideas or statements held as an explanation or account of a group of facts or phenomena; a hypothesis that has been confirmed or established by observation or experiment, and is propounded or accepted as accounting for the known facts; a statement of what are known to be the general laws, principles, or causes of something known or observed."
} 
is an explanation, or account, of why concrete acts ${ }^{3}$ possess the properties they do-properties such as rightness, fairness, goodness, justice, and praiseworthiness. (A given act may be right or wrong; fair or unfair; good, bad, or indifferent; just or unjust; praiseworthy or blameworthy.)

Theories are Janus-faced, in that they are both backward-looking and forward-looking. A scientific theory, whether natural or social, both explains what is (including how it came to be) and serves as the basis for predicting and controlling events (including human actions). These events are necessarily in the future. A normative ethical theory provides an account of right-making characteristics, but also provides a reason for action. To someone who is motivated to do the right thing, but who doesn't know what the right thing is, an account of what makes an act right (as opposed to wrong) is useful knowledge. For example, if what makes an act right is that it maximizes overall happiness, and I know this, then, to the extent that I desire to act rightly, I will strive to maximize overall happiness. This, incidentally, is what it means to say that a theory is normative (as opposed to positive). It identifies norms or standards by which, or in accordance with which, one may guide one's behavior.

A person can be interested in the backward-looking aspect of a theory without being interested in its forward-looking aspect. In physical theory, for example, one may have no interest in predicting the behavior of physical objects (although, as a matter of fact, most physicists are interested in prediction). In economic theory, one may have no interest in controlling economic events (although, as a matter of fact, most economists are interested in control). By the same token, a normative ethical theorist may have no interest in using the theory to guide action. He or she may simply want to understand what it is that makes right acts right and wrong acts wrong. The interest of such a person is theoretical rather than practical. The theorist seeks a criterion (of rightness) rather than a decision-making procedure.

\section{Normative Ethical Theories}

Moral philosophy has a rich and fascinating history. A great many thinkers have approached the subject from a wide variety of perspectives, producing theories that both attract and repel the thoughtful reader. Almost all the classical theories contain plausible elements, which is hardly surprising, considering that they were devised by philosophers of undoubted genius. Yet the various theories are not consistent with one another, and most are vulnerable to crippling objections. After reviewing them, one is left wondering what to believe. What, in the final analysis, is the truth? (Rachels \& Rachels, 2007: p. 191).

Now that we have identified the common feature of theories, or that which

${ }^{3} \mathrm{~A}$ concrete act (i.e., an act token) is a unique, unrepeatable act (informally, a "one-off"), such as my writing this sentence at this moment. A generic act (i.e., an act type) is a kind of act, such as my writing, my writing a philosophical article, or my writing a philosophical article on an ethical topic. As this second example shows, generic acts can be more or less specific. Concrete acts are particulars. 
makes them theories and not something else, let us focus in the remainder of this article on normative ethical theories. Ultimately, we want to know how one goes about defending a theory of that sort.

A normative ethical theory is a statement of necessary and sufficient conditions for moral rightness. A condition is necessary when it must be satisfied in order for a particular act to be right. A condition is sufficient when its satisfaction is enough (i.e., all it takes) for the act in question to be right. Think of a normative ethical theory as a sorting device. It sorts concrete acts into two jointly exhaustive and mutually exclusive categories: "right" (i.e., permissible) and "wrong" (impermissible). Different theories sort acts differently. This doesn't mean that there is no overlap between the theories, for two or more theories may sort the same act as "right" (or "wrong"). What it means is that no two theories sort acts in exactly the same way. If they did, they would be one theory and not two. ${ }^{4}$

Normative ethical theories are rivals for allegiance. Think of the various theories as contending (or competing) for adherents (or subscribers). For any two normative ethical theories, it is logically impossible for both to be true, but logically possible for both to be false. For example, egoism and act utilitarianism cannot both be true, because they provide different criteria for moral rightness. But both can be false. Kantianism or contractarianism (or some other theory) may be the true or correct account of moral rightness. Propositions that cannot both be true, but can both be false, are said to be contraries (as opposed to contradictories, which cannot both be true and cannot both be false). ${ }^{5}$ Normative ethical theories are contraries (of one another). It could turn out that all extant normative ethical theories are false. Perhaps the true or correct account of moral rightness has yet to be discovered (or formulated).

\section{Defending a Normative Ethical Theory}

If one holds a view in moral philosophy, how is it to be supported? Basically, there are two ways. One is to argue in favor of one's own position either positively by stating reasons for holding it or defensively by answering objections to it. The other is to show that there are problems with alternative views (West, 2004: p. 28).

In this, the longest section of the article, I describe what I call "a complete defense" of a normative ethical theory. Later, I will discuss various "incomplete" or "partial" defenses, showing how they differ from "complete" defenses and explaining why someone might opt for a partial defense in spite of its incompleteness.

A complete defense of a normative ethical theory has five components, which I call "underpinning," "undermining," "countermining," "attacking," and "repelling." As may be surmised, these terms are drawn from warfare. (Philosophy

${ }^{4}$ They would be extensionally (though not intensionally) equivalent.

${ }^{5}$ For further discussion of these points, see the Appendix. 
may be thought of as cognitive warfare.) For purposes of illustration, let egoism be our theory. Egoism has been formulated in different ways by different people (including by its opponents), ${ }^{6}$ so let us pick a formulation that is clear and simple. According to textbook author Fred Feldman, egoism is the theory (or principle) that "an act is morally right if and only if no alternative to that act has higher agent utility than it has" (Feldman, 1978: p. 82). Agent utility is "the result of subtracting the sum of the doloric values of all the episodes of pain felt by the agent of the act as a result of the act, from the sum of the hedonic values of all the episodes of pleasure felt by the agent of the act as a result of the act" (Feldman, 1978: p. 82). Egoism may be thought of as the identification of morality with enlightened (i.e., long-term, rational) self-interest.

\subsection{Underpinning 7}

The first component of a complete defense is underpinning. This consists in providing reasons for the truth of one's theory (in this case, egoism). The idea is that the theory needs support (underpinning). I don't merely assert egoism, or claim that it is true; I argue for it. I provide reasons why others should believe it, accept it, adhere to it, subscribe to it, and (ultimately) act on it. Ideally, I, an egoist, would make every plausible argument for the truth of my theory.

An argument for a normative ethical theory has three possible audiences: first, those who (already) believe it to be true; second, those who (already) believe it to be false; and third, those who neither believe it to be true nor believe it to be false. One might wonder why I would argue for egoism to someone who already believes it. The reason is that the person who believes it may have inadequate grounds (at the limit, no grounds) for doing so. My aim is to justify the theory, so that it becomes a candidate for knowledge. (Whatever else knowledge is, it requires that the belief in question be justified.) For those who believe egoism to be false, I am trying to change minds. For those who neither believe egoism to be true nor believe it to be false, I am trying to induce belief in its truth. Argumentation of this sort-what we might call "reason-giving"-is not merely common in philosophy; it is characteristic (some would say constitutive) of it.

How do I argue for (i.e., underpin) egoism? In his textbook entitled Introductory Ethics, Feldman asks, "What reason is there to believe that egoism is true? What arguments have been given in favor of this normative theory?" (Feldman, 1978: p. 86). He proceeds to discuss two arguments, which he calls "Closet Utilitarian Argument" and "Motivation Argument." Each of these arguments has as its conclusion the theory that we are calling egoism (formulated as above). Here, for example, is the Motivation Argument (Feldman, 1978: p. 89):

1) A person can perform an act only if that act has at least as much agent utility as any alternative.

\footnotetext{
${ }^{6}$ For some of the varieties (formulations) of egoism, see Burgess-Jackson, 2003: pp. 359-362.

"“Underpin" (verb) means "support (a building or other structure) from below by laying a solid foundation below ground level or by substituting stronger for weaker materials" (New Oxford American Dictionary, 2010: p. 1884).
} 
2) A person is morally obligated to perform an act only if he can perform it.

3) If a person can perform an act only if that act has at least as much agent utility as any alternative, and if a person is morally obligated to perform an act only if he can perform it, then it is right for a person to perform an act if and only if it has at least as much agent utility as any alternative.

Therefore,

4) It is right for a person to perform an act if and only if it has at least as much agent utility as any alternative; in other words, egoism is true (from 1, 2, and 3).

Feldman concludes-after careful analysis-that the Motivation Argument is unsound, but that is neither here nor there as far as our discussion is concerned. My point in quoting the argument is simply to show the reader how one goes about underpinning a theory.

It must be kept in mind that while $I$ am underpinning my theory (egoism), other theorists (act utilitarians and Kantians, for example) are underpinning their theories. Imagine a valley in which there are several fortifications, each of which represents a normative ethical theory. Those who inhabit the fortifications are at war with (and, as a result, wary of) each other. Each vies for the support not only of those who enter the valley from outside, but of those who inhabit other fortifications. There is a sense, therefore, in which the inhabitants of the various fortifications are rivals. They are competing with one another for adherents. To win adherents, they must remain viable. The stronger my fortification, the more likely it is to withstand assault from my (our) enemies. Underpinning is therefore best thought of as a defensive measure. As we shall see, some of the components of a complete defense of a normative ethical theory are defensive measures and some are offensive measures. A "complete defense" (as I call it) is neither purely defensive nor purely offensive; it is a mixture of the two.

\subsection{Undermining8}

Let us turn to our first offensive measure. I said in the previous paragraph that while I am busy underpinning my theory, other theorists are busy underpinning (i.e., constructing arguments in favor of) theirs. The second component of a complete defense is undermining. This consists in finding fault with the arguments that underpin rival theories. Ideally, I, an egoist, would criticize (find fault with) every argument for the truth of every rival theory. "Find fault with" means showing that an argument is unsound. There are two ways for a deductive argument to be unsound. The first is by being invalid. I may be able to show that the premises of the argument in question do not logically imply, or entail, its conclusion. In other words, even if the premises of the argument are true, they do not establish the truth of the conclusion. The second way for a deductive argument to be unsound is by having at least one false premise. Some arguments are doubly defective, in that they are invalid and have at least one false premise.

Here is an example of undermining. In his book Utilitarianism (1861), John

"Undermine" (verb) means "dig or excavate beneath (a building or fortification) so as to make it collapse” (New Oxford American Dictionary, 2010: p. 1883 [first definition]). 
Stuart Mill (1957) made a famous argument in favor of act utilitarianism (which he called, simply, "utilitarianism"). Feldman reconstructs "Mill's Proof" as follows: ${ }^{9}$

1) Each person desires his own happiness.

2) If each person desires his own happiness, then each person can desire his own happiness.

3) If each person can desire his own happiness, then each person's happiness is desirable for that person.

4) If each person's happiness is desirable for that person, then each person's happiness is a good to that person.

Therefore,

5) Each person's happiness is a good to that person (from 1 through 4).

6) If each person's happiness is a good to that person, then the general happiness is a good to the aggregate of people.

7) If the general happiness is a good to the aggregate of people, then the general happiness is a criterion of morality.

Therefore,

8) The general happiness is a criterion of morality (from 5 through 7).

9) People can desire nothing other than parts of or means to happiness.

10) If people can desire nothing other than parts of or means to happiness, then nothing other than happiness is a criterion of morality.

Therefore,

11) Nothing other than happiness is a criterion of morality (from 9 and 10).

Therefore,

12) Happiness is the sole criterion of morality (from 8 and 11).

According to Feldman, the grand conclusion of this argument, proposition 12, is a paraphrase of act utilitarianism, which says that "[a]n act is right if and only if there is no other act the agent could have done instead that has higher utility than it has" (Feldman, 1978: p. 26). The argument, therefore, is an argument for (i.e., in support of) act utilitarianism. It is an attempt-by Mill—to underpin his theory.

Feldman is not impressed by Mill's argument. He says that it has several defects, including committing the fallacy of equivocation (by "fail[ing] to distinguish between two different senses of the word 'desirable"'), committing the fallacy of composition ("inferring from the fact that all the members of a group have a certain property, that the group as a whole has that property"), and being intolerably obscure ("What does Mill mean when he speaks of 'the general happiness'?"). Feldman's verdict is that Mill has produced "an extremely weak argument" (Feldman, 1978: p. 46).

If Feldman's verdict is correct, then he has undermined act utilitarianism. Metaphorically speaking, he has dug or excavated beneath the fortification ${ }^{9}$ Feldman presents the argument in three stages, on pages 42 through 44 of his textbook. I combine the stages. I also tinkered with the wording, changing "for" to "to" on two occasions (for the sake of consistency). 
(theory) so as to make it collapse. (We might say that the underpinning of the theory, by Mill, failed to support it.) In doing this, Feldman helps the egoist, the contractarian, the Kantian, and every other rival theorist. Ideally, as we saw earlier, I, an egoist, would criticize (find fault with) every argument for the truth of every rival theory. This is only an ideal, for, given various practical limitations (such as having a finite amount of time), no theorist could possibly find fault with more than a handful of arguments for each significant rival theory. I shall return to the divergence between the ideal and the non-ideal, or between theory and practice, in a subsequent section of the article.

Before leaving the topic of undermining, let me dispel a potential confusion. Suppose Jones shows that a particular argument for a particular rival theory is defective. Jones has undermined the theory by destroying one of its pins or pillars. This does not mean that Jones has proved the theory false. It may well be true. All Jones has done is destroy one of the theory's supports, or one reason for thinking the theory true. "Very well," Jones might say; "suppose I destroy all the theory's supports, i.e., all known arguments for the truth of the theory. Haven't I proved the theory false?" The answer is no. There may, despite Jones's best efforts, be an argument that proves the theory true. Creativity in philosophy consists largely in devising new arguments for and against various theories or theses.

We saw earlier that, while $I$ am busy underpinning my theory, each rival theorist is doing the same with respect to his or her theory. The same phenomenon applies here. While I, an egoist, am undermining other theories (such as act utilitarianism), my rivals-act utilitarians, Kantians, contractarians, and others-are attempting to undermine $m y$ theory. Everyone is trying to undermine everyone else's theory! What, if anything, can I do about this?

\subsection{Countermining10}

Let us turn to our second defensive measure. (The first was underpinning.) The third component of a complete defense is countermining, or countering an attempt to undermine. This consists in replying to the objections raised (by rival theorists) against my supporting arguments. Ideally, I, an egoist, would reply to every criticism of every argument for the truth of my theory. You may recall that I used Feldman's Motivation Argument as an example of underpinning. Feldman himself objects to this argument, claiming that two of its three premises-1 and 3-are false. In doing so, Feldman tries to undermine one of the supports for the theory (egoism).

To counter this attempt to undermine, I, the egoist, must show that Feldman's allegations of falsity (of the two premises) are themselves false. I will have to explain why, pace Feldman, the two premises are true. If Feldman constructs an argument for the falsity of premise 1 or premise 3 (or both), I will have to criticize (find fault with) that argument (or those arguments). Had Feldman claimed that the Motivation Argument is invalid, I would have had to explain why he is

10"Countermine" (verb) means "dig a countermine against" (New Oxford American Dictionary, 2010: p. 396). A countermine is “an excavation dug to intercept another dug by an enemy” (ibid.). 
wrong about that. Had Feldman claimed that the Motivation Argument is obscure (and therefore incapable of being evaluated), I would have had to eliminate the obscurity. Countermining means doing whatever is necessary to prevent undermining. It means protecting the pins or pillars that support one's theory.

It might be wondered whether I am the only theorist engaged in countermining. The answer is no. Recall that, in addition to underpinning and countermining, I am busy trying to undermine rival theories. As I do this, the proponents of those theories are doing their best to countermine my attempts to undermine. That is to say, they are busy replying to my objections to their arguments. Must I stand by as they do this? Of course not. I can (and should) try to find fault with their replies. I have not given a name to this strategy (of thwarting a countermine). Perhaps we could call it a "counter-countermining." In general, every strategy deployed in normative ethics can be met with a counter-strategy. I have arbitrarily limited the number of strategies to five, but I could just as easily have expanded the number to eight or 10 or more. Philosophical argumentation is like a tennis match. The ball goes from one side of the court to the other until someone either fails to hit it back (signifying defeat) or gets tired of playing (signifying boredom).

\subsection{Attacking11}

Let us turn to our second offensive measure. (The first was undermining.) The fourth component of a complete defense is attacking. This consists in constructing an argument for the falsity of a rival theory. Ideally, I, an egoist, would make every plausible argument for the falsity of every rival theory. The greater the number of sound arguments there are for the falsity of each rival theory, the better it is for my own theory. It must be borne in mind that no argument for the falsity of a rival theory, even if sound, shows that egoism is true. We saw earlier that rival theories are contraries, not contradictories (of one another). This means that they cannot all be true but may all be false. Even if I show that every rival of egoism is false, therefore, I do nothing to show that egoism is true. Egoism may be as false as its rivals.

What would an attack on a rival theory look like? Act utilitarianism is a rival of egoism, so let us use it as our example. To show that act utilitarianism is false (or, what comes to the same thing, not true), I argue as follows (Feldman, 1978: p. 60 [not verbatim]):

1) If act utilitarianism is true, then the only moral reason for preferring one distribution of goods over another is that the one would produce more utility than the other.

2) It is not the case that the only moral reason for preferring one distribution of goods over another is that it would produce more utility than the other; another reason is that one might be more just than the other.

Therefore,

\footnotetext{
11"Attack" (verb) means "take aggressive action against (a place or enemy forces) with weapons or armed force, typically in a battle or war" (New Oxford American Dictionary, 2010: p. 103).
} 
3) Act utilitarianism is not true (from 1 and 2).

Attacking is a way of eliminating rivals. I will need to make as many arguments as there are rivals, so as to eliminate all of them and leave my own theory, egoism, as the only one standing. Indeed, I will need to do more than this. I will need to make every (plausible) argument I can think of for the falsity of each rival. Egoism's rivals include act utilitarianism, rule utilitarianism, Kantianism, conventionalism, Hobbesian contractarianism, Rawlsian contractarianism, theological voluntarism, natural law, the Golden Rule, virtue theory, and Rossian pluralism. That is a lot of arguments! But remember: a complete defense is an (unattainable) ideal. In the real world, we will have to make do with less than the best. I will say more about this in the next section (Section 5) of the article.

\subsection{Repelling12}

Let us turn to our third defensive measure. (The first two were underpinning and countermining.) Ideally, I, an egoist, would criticize (find fault with) every argument for the falsity of my theory. Feldman presents an argument that he believes "refutes" egoism. His argument makes reference to a hypothetical case, so, to understand the argument, we must recite the facts of the case:

A man is the treasurer of a large pension fund. He is entrusted with the job of keeping track of and investing the money deposited by the workers. When a worker retires, the worker is entitled to draw a weekly sum from the fund. Suppose the treasurer discovers that it will be possible for him to use all the money for his own selfish pleasure without being caught. Perhaps he wants to buy a large yacht and sail to a South Sea island, there to live out his days in idleness, indulgence, procreation, and, in a word, enjoyment. Since there is no extradition treaty between the South Sea island and the United States, he can get away with it (Feldman, 1978: p. 95).

Feldman continues:

Let us also suppose that if the treasurer does abscond with the funds, hundreds of old people will be deprived of their pensions. They will be heartbroken to discover that instead of living comfortably on the money they had put into the pension fund, they will have to suffer the pain and indignity of poverty (Feldman, 1978: p. 95).

The treasurer can perform either of two acts: first, steal the money, which (we will suppose) has agent utility of $+10,000$; second, leave the money where it is, which (we will suppose) has agent utility of -3 . Since no alternative to the first act has higher agent utility than it has, the first act is right, according to egoism. Here is Feldman's argument ("Pension Argument") for the falsity (i.e., non-truth) of egoism (Feldman, 1978: p. 96 [not verbatim]):

1) If egoism is true, then stealing the money (in the hypothetical case) is mo-

12"Repel” (verb) means "drive or force (an attack or attacker) back or away" (New Oxford American Dictionary, 2010: p. 1479 [first definition]). 
rally right.

2) Stealing the money (in the hypothetical case) is not morally right.

Therefore,

3) Egoism is not true (from 1 and 2).

Feldman concludes that " $\mathrm{t}]$ his argument decisively refutes egoism, as do an enormous number of other arguments along the same lines" (Feldman, 1978: p. 96).

Can the egoist repel Feldman's attack? The Pension Argument is an instance of a valid argument form (namely, Modus Tollens), so it, too, is valid. ${ }^{13}$ This means that the egoist has only two available strategies: first, reject the first premise; second, reject the second premise. The first premise says, in effect, that egoism implies that it's right for the treasurer to steal the money. The egoist can reply that this proposition is false: the theory has no such implication.

One way of establishing this claim is to show that agent utility has been improperly calculated. For example, even though there is (ex hypothesi) no extradition treaty between the South Sea island and the United States, the treasurer isn't safe until he arrives on the island. There is always a nonzero probability that he will be apprehended before he leaves the jurisdiction of the United States, in which case he will (or may) be indicted, tried, convicted, and punished (possibly severely). There is also a nonzero probability that family and friends of the victimized pensioners will track the treasurer down and return him to the United States (or worse, torture and kill him). There is also a nonzero probability that, when word gets out among the islanders about what the new resident did to become wealthy, they will take the law into their own hands and "punish" him (perhaps hoping, thereby, to appease the United States). When these probabilities (and others) are taken into account, the egoist says, the act of stealing the money no longer maximizes agent utility; and if it no longer maximizes agent utility, then it is not right, according to egoism.

Instead of rejecting the first premise (which is called "grasping the bull by the horn"), the egoist might reject the second. ${ }^{14}$ This would mean asserting that stealing the money is morally right. It may be painful for an egoist to assert this (which is why it's called "biting the bullet"), but it can be done. It amounts to sticking with one's theory even when the theory has disturbing ("painful") implications. Act utilitarians such as J. J. C. Smart (1980) and Peter Singer are notorious bullet biters; there is no reason why an egoist cannot adopt the same strategy. Either every theorist gets to bite bullets or no theorist gets to bite bullets. $^{15}$

We have now discussed-and illustrated - the five components of a complete

\footnotetext{
${ }^{13}$ Any argument that has a valid form is a valid argument.

${ }^{14}$ The premises of a Modus Tollens argument form are subcontraries. This means that, while it is logically possible for both premises to be true, it is logically impossible for both to be false. It would be irrational, therefore, for someone to reject both premises. One may reject the first premise (while accepting the second); one may reject the second premise (while accepting the first); but one may not reject both premises.

${ }^{15}$ See Burgess-Jackson, 2013a.
} 
defense of a normative ethical theory. The discussion has been somewhat abstract. It is time to bring it down to earth.

\section{The Ideal and the Non-Ideal}

We might therefore do well to consider how a philosophical judge might develop, in appropriate cases, theories of what legislative purpose and legal principles require.... I have invented, for this purpose, a lawyer of superhuman skill, learning, patience, and acumen, whom I shall call Hercules (Dworkin, 1978: p. 105).

I have used the words "ideal" or "ideally" many times in this article, as in, "Ideally, I, an egoist, would criticize (find fault with) every argument for the truth of every rival theory." My aim in using these words is to describe a perfect world, one in which there are no limitations of time, energy, imagination, or understanding. More precisely, it is to describe a perfect normative ethical theorist, one who, like Ronald Dworkin's (1978) imaginary judge Hercules, has "superhuman skill, learning, patience, and acumen."

Obviously, ours is not such a world, and there is (alas) no superhuman normative ethical theorist (though Henry Sidgwick comes close). We live in the real world, which is one of many possible non-ideal worlds. In the real world, time is short (we have much to do besides philosophize, thank goodness), energy limited (we are biological organisms with physical needs and frailties), imagination impoverished (or altogether lacking), and understanding deficient (even geniuses are not omniscient). If we cannot attain the Herculean ideal, what can we attain, or hope to attain?

We can attain the following. Instead of making every plausible argument for the truth of one's theory, which is beyond one's all-too-human capacities, one can make at least one plausible argument for the truth of one's theory (or perhaps a few of what one considers the strongest arguments: those that are least likely to be undermined by the theory's critics). Instead of criticizing (finding fault with) every argument for the truth of every rival theory, one can criticize (find fault with) at least one argument for the truth of at least one rival theory (or perhaps some arguments-the strongest ones-for the truth of each of the main rival theories). Instead of replying to every criticism of every argument for the truth of one's theory, one can reply to at least one criticism of at least one argument for the truth of one's theory (or perhaps the strongest criticisms of some subset of those arguments [preferably the strongest ones]). Instead of making every plausible argument for the falsity of every rival theory, one can make at least one plausible argument for the falsity of at least one rival theory (or perhaps each of the main rival theories). Instead of criticizing (finding fault with) every argument for the falsity of one's theory, one can criticize (find fault with) at least one argument for the falsity of one's theory (or perhaps the strongest arguments).

Think of this as theoretical defense for humans, as opposed to superhumans. 
Obviously, the more time, energy, and resourcefulness one has at one's disposal, the greater the number of arguments one can make and the greater the number of criticisms one can offer. Does this mean that the ideal of a complete defense is unimportant? No. Ideals are important even if (or even though) they are unattainable. First, they inspire. Knowing that my defense of my theory falls short of what it might be (as described by the ideal), I redouble my efforts. Second, they provide benchmarks. My defense of my theory may be better today than it was a year ago, or five years ago, and it may be better next year than it is today. Perhaps I could think of only three plausible arguments for my theory at some time in the past. I may now have four or five plausible arguments. This is progress. The ideal helps me measure it.

The reverse is also true. Suppose I have what I consider to be three plausible arguments for my theory. I may be persuaded by a critic that one of them is weak. This may cause me to delete it from my inventory (i.e., to stop making that argument). While this may seem like regression, it is actually progress, because it's not just the quantity of arguments that one has for one's theory that matters; it's their quality. Two strong arguments are better than two strong arguments and one weak argument. Two strong arguments are better than three weak(er) arguments.

\section{The Complete and the Incomplete}

I think that I was too optimistic in the past in thinking that people would reject utilitarianism only if they were not benevolent on the one hand, or philosophically confused on the other hand. I think that all one can do is to present the act utilitarian system, refute various specious objections which have been and still are being brought against it, and see whether any of one's audience find it attractive. If some of them do not, I do not now think that it follows that they must be lacking in benevolence (Smart, 1980: pp. 120-121).

A complete defense, whether ideal or non-ideal, has, as we have seen, five components. An incomplete (i.e., partial) defense has fewer than five components. An example of the latter is provided by J. J. C. Smart in the quotation preceding this paragraph. Smart gives an incomplete defense of act utilitarianism not because he is lazy or unimaginative, but because he is a non-cognitivist. His view is that normative ethical theories such as act utilitarianism are neither true nor false. They are not truth-apt. Since he doesn't claim that his theory is true, he doesn't argue for its truth. That is, he doesn't underpin it. Since he doesn't claim that rival theories are false, he doesn't attack them. Since he doesn't argue for his theory, there are no arguments for others to undermine, and hence nothing for him to countermine. All he can do, given his non-cognitivism, is undermine (i.e., find fault with arguments for the truth of rival theories) and repel (find fault with arguments for the falsity of act utilitarianism).

Should we say that Smart's defense of his theory (act utilitarianism) is a fail- 
ure? We should not. It is merely incomplete. An incomplete (partial) defense is still a defense. In some cases, the reason why a theorist provides only a partial defense is that he or she is still working on other components of the defense. I may begin my defense of my theory by underpinning it. Later, once this task is accomplished, I may commence my attacks on rival theories. When this is done, I may proceed to undermine, countermine, and repel. As this shows, a complete defense may be provided all at once (in the form of a monograph, for example) or seriatim (as a series of articles or reviews). When we combine this distinction (between complete and incomplete defenses) with the distinction drawn in Section 5 (between ideal and non-ideal defenses), we get four possibilities, as represented in the following diagram:

\begin{tabular}{|c|c|c|}
\hline & Complete & Incomplete \\
\hline Ideal & $\begin{array}{l}\text { 1a. Underpin (defensive): Make every plausible argument for } \\
\text { the truth of my theory. } \\
\text { 2a. Undermine (offensive): Criticize (find fault with) every } \\
\text { argument for the truth of every rival theory. } \\
\text { 3a. Countermine (defensive): Reply to every criticism of every } \\
\text { argument for the truth of my theory. } \\
\text { 4a. Attack (offensive): Make every plausible argument for the } \\
\text { falsity of every rival theory. } \\
\text { 5a. Repel (defensive): Criticize (find fault with) every argument } \\
\text { for the falsity of my theory. }\end{array}$ & $\begin{array}{l}\text { A proper subset } \\
\text { of 1a through } 5 a \text {. }\end{array}$ \\
\hline Non-Ideal & $\begin{array}{l}\text { 1b. Underpin (defensive): Make at least one plausible argument } \\
\text { for the truth of my theory. } \\
\text { 2b. Undermine (offensive): Criticize (find fault with) at least one } \\
\text { argument for the truth of at least one rival theory. } \\
\text { 3b. Countermine (defensive): Reply to at least one criticism of at } \\
\text { least one argument for the truth of my theory. } \\
\text { 4b. Attack (offensive): Make at least one plausible argument for } \\
\text { the falsity of at least one rival theory. } \\
\text { 5b. Repel (defensive): Criticize (find fault with) at least one } \\
\text { argument for the falsity of my theory. }\end{array}$ & $\begin{array}{l}\text { A proper subset } \\
\text { of } 1 \mathrm{~b} \text { through } 5 \mathrm{~b} \text {. }\end{array}$ \\
\hline
\end{tabular}

Another example of a non-ideal defense (besides that of Smart) may be instructive. Here, once again, is the quotation from Henry West that served as the epigraph of Section 4:

If one holds a view in moral philosophy, how is it to be supported? Basically, there are two ways. One is to argue in favor of one's own position either positively by stating reasons for holding it or defensively by answering objections to it. The other is to show that there are problems with alternative views (West, 2004: p. 28).

Let us assume that by "supported," West means "defended." The first thing the theorist does is "stat[e] reasons for holding" his or her theory. This is what I call underpinning. The second thing the theorist does is "answer[] objections" to his or her theory. This is what I call repelling. (If the objections in question go to the arguments I make in support of my theory, as opposed to the theory itself, then West 
is describing what I call countermining.) The third thing the theorist does is "show that there are problems with alternative views." This is what I call attacking. (If the problems are with the rival theorists' arguments for their theories, as opposed to the theories themselves, then West is describing what I call undermining.)

Depending on how we interpret "answering objections" and "show[ing] that there are problems," West is providing either a complete non-ideal defense or a partial non-ideal defense. There are many other examples of partial defenses in the literature of normative ethics, but this is enough to make the point. Let us now turn to a third distinction.

\section{The Successful and the Unsuccessful}

success word A word whose application entails the truth of an embedded clause, or the achievement of some result. 'I remember, know, realize, perceive that $p$ ' all imply the truth of $p$. Many words describing our knowledge of things presuppose success or achievement. We can only know what is true, remember what happened, or perceive what is there. Other words have to be found for illusions of knowing, remembering, or perceiving, suggesting that success is a kind of default state (Blackburn, 2008: p. 353 [boldface and italics in original]).

Many people use the word "refute" when they mean "rebut," and "rebut" when they mean "refute." The difference is that "refute" is a success word, while "rebut" is not. One can try to refute (i.e., disprove) and fail to do so, but if one refutes, then one necessarily succeeds (in disproving). This is not the case with "rebut." If one rebuts (i.e., claims to disprove), then one does not necessarily succeed (in disproving).

The title of this article is "How to Defend a Normative Ethical Theory." Is "defend" a success word, like "refute," or does it function like "rebut"? The answer is that it is not a success word. A given defense can be successful or unsuccessful. In a court of law, for example, some insanity defenses succeed and some fail. It makes perfect sense for a defense attorney to say to a colleague, "I thought the insanity defense was my best option, but it failed." In a military situation, my attempt to defend my fortification from attack may succeed or fail. If my compatriots and I are overwhelmed by the enemy, then our defense, however spirited, failed. If we repulse the enemy, then we have succeeded-at least for the time being. ${ }^{16}$

A defense of a normative ethical theory can either succeed or fail. The first

${ }^{16}$ Here is an alternative explanation. "Refute" (verb) means "prove (a statement or theory) to be wrong or false; disprove" (New Oxford American Dictionary, 2010: p. 1468). By definition (literally!), if I refute theory $\mathrm{T}$, then I succeed in proving $\mathrm{T}$ to be false. "Rebut" (verb) means "claim or prove that (evidence or an accusation) is false" (ibid., p. 1455 [first definition]). By definition, if I rebut theory $\mathrm{T}$, then I succeed in claiming that $\mathrm{T}$ is false, but may or may not succeed in proving that $\mathrm{T}$ is false. "Defend" (verb) means "resist an attack made on (someone or something); protect from harm or danger" (ibid., p. 454). "Resist" (verb) means "try to prevent by action or argument" (ibid., p. 1485). By definition, if I defend theory $\mathrm{T}$, then I succeed in trying to prevent an attack on $\mathrm{T}$, but may or may not succeed in preventing an attack on T. "Defend," in short, does not have success built into it, as "refute" does. 
component of a complete defense, as we saw in Section 4, is underpinning, which means making every plausible argument for the truth of my theory. My "plausible argument" may, unbeknownst to me, be unsound, either because it is invalid or because it has a false premise. (I may have confused Modus Ponens with the Fallacy of Affirming the Consequent; or I may have made an honest mistake about the facts.) The second component of a complete defense is undermining, which means criticizing (finding fault with) every argument for the truth of every rival theory. My "criticism" of a particular argument may, despite my best efforts, be ineffective in showing that the argument is unsound. Perhaps I think that the argument commits a fallacy, when in fact it does not. Similar things can be said about the other three components of a complete defense.

Since a complete defense of a normative ethical theory may either succeed or fail, we must be prepared to say such things as, "Smith's complete defense of theory T was unsuccessful [a failure]," or "Smith's complete defense of theory T was successful [a success]," or "Smith's complete defense of theory T was partially successful; while Smith succeeded in attacking rival theory $\mathrm{U}$, her attempt to underpin her theory was a failure." Obviously, it is better to succeed than to fail, at least when it comes to defending something valuable (such as a theory that one believes to be true). The purpose of this article is not to provide tips on how to increase the likelihood of success in such an endeavor, but to explain how one goes about defending a normative ethical theory. The purpose, in other words, is to describe five things that must be done successfully in order to succeed in providing a complete defense.

\section{Conclusion}

Believing that the major task of ethics is to delineate the correct or best justified principle or set of principles for distinguishing right from wrong, moral philosophers have advanced an impressively diverse array of normative theories. Kantians, social contract theorists such as Rawls, utilitarians, commonsense pluralists, and others less easily categorized have put forward a plethora of rival principles, intended to guide our moral decision-making and to explain why certain acts are right and others wrong. Much of academic moral philosophy consists in dialogue and argument among and between representatives of these different camps (Shaw, 1999: p. 246).

The purpose of this article is to make explicit and systematic what philosophers do implicitly and haphazardly. When philosophers defend normative ethical theories such as Kantianism, egoism, contractarianism, and act utilitarianism, they do several different things. First, they support their theories. I call this "underpinning." Second, they criticize (find fault with) the arguments that other theorists (their rivals) advance for their theories. I call this "undermining." Third, they reply to objections to their own supporting arguments. I call this "countermining." Fourth, they argue that rival theories are false. I call this "attacking." Fifth, they reply to arguments that their own theories are false. I call 
this "repelling." I have argued that a "complete defense" of a normative ethical theory combines all five of these components. ${ }^{17}$

Having identified the five components of a complete defense, I distinguished between those that are ideal (aspirational) and those that are non-ideal. I then distinguished between complete and incomplete (partial) defenses. A partial defense is better than no defense at all, but not as good as a complete defense, even if the complete defense is non-ideal. Finally, I distinguished between successful and unsuccessful defenses. "Defend," unlike "refute," is not a success word. In this respect it is like "rebut." Some rebuttals succeed (in disproving); some do not. Some defenses succeed (in protecting); some do not. Whether a given defense succeeds depends on the soundness of the arguments being advanced or criticized. A complete defense of a normative ethical theory that is both ideal and successful may be beyond human capabilities, but it is not on that account useless. It has the same status as the New Testament dictum, "You shall love your neighbor as yourself." 18

\section{Acknowledgements}

This article is dedicated to the memory of Leslie Howard ("Les") Kutinsky (1933-2019), who took a chance on me.

\section{Conflicts of Interest}

The author declares no conflicts of interest regarding the publication of this paper.

\section{References}

Blackburn, S. (2008). The Oxford Dictionary of Philosophy (2nd ed.). New York, NY: Oxford University Press.

Burgess-Jackson, K. (2003). Deontological Egoism. Social Theory and Practice, 29, 357-385. https://doi.org/10.5840/soctheorpract200329321

Burgess-Jackson, K. (2013a). Taking Egoism Seriously. Ethical Theory and Moral Practice, 16, 529-542. https://doi.org/10.1007/s10677-012-9372-5

Burgess-Jackson, K. (2013b). Ethical Egoism. In J. E. Crimmins (Ed.), The Bloomsbury Encyclopedia of Utilitarianism (pp. 142-145). New York, NY: Bloomsbury Academic.

Burgess-Jackson, K. (2013c). Psychological Egoism. In J. E. Crimmins (Ed.), The Bloomsbury Encyclopedia of Utilitarianism (pp. 449-450). New York, NY: Bloomsbury Academic.

Dworkin, R. (1978). Taking Rights Seriously. Cambridge, MA: Harvard University Press.

Feldman, F. (1978). Introductory Ethics. Upper Saddle River, NJ: Prentice-Hall.

Kagan, S. (1998). Normative Ethics. Boulder, CO: Westview Press.

Mill, J. S. (1957). Utilitarianism. Indianapolis: Bobbs-Merrill Educational Publishing.

New Oxford American Dictionary (2010). New Oxford American Dictionary (3rd ed.). New York: Oxford University Press.

\footnotetext{
${ }^{17} \mathrm{My}$ hope is that "a complete defense" becomes a term of art in the discipline.

${ }^{18}$ Matthew 22:39 (NRSV).
} 
Oxford English Dictionary (1971). Oxford English Dictionary (Compact ed.). Oxford: Oxford University Press.

Rachels, J. (1974). Two Arguments against Ethical Egoism. Philosophia, 4, 297-314. https://doi.org/10.1007/BF02379228

Rachels, J., \& Rachels, S. (2007). The Elements of Moral Philosophy (5th ed.). New York, NY: McGraw-Hill.

Shaw, W. H. (1999). Contemporary Ethics: Taking Account of Utilitarianism. Malden, MA: Blackwell Publishers.

Smart, J. J. C. (1980). Utilitarianism and Generalized Benevolence. Pacific Philosophical Quarterly, 61, 115-121. https://doi.org/10.1111/j.1468-0114.1980.tb00008.x

Timmons, M. (2002). Moral Theory: An Introduction. Lanham, MD: Rowman \& Littlefield Publishers.

West, H. R. (2004). An Introduction to Mill's Utilitarian Ethics. Cambridge: Cambridge University Press. 


\section{Appendix}

A complete defense of a theory differs from a complete defense of a thesis. A theory has both a negation (i.e., a contradictory) and (one or more) rivals. For example, act utilitarianism and Kantianism are rival normative ethical theories. As explained in the main body of this article (specifically, Section 3), they cannot both be true, but they can both be false. This makes them contraries (of one another). A thesis, by contrast, has a negation (i.e., a contradictory) but no rivals. For example, the negation of the thesis that God exists is the thesis that God does not exist (i.e., the thesis that it is not the case that God exists). The two theses cannot both be true; nor can they both be false. This makes them contradictories (of one another).

Suppose I wish to provide a complete defense of theory T. I have five tasks (as explained in the main body of the article):

1) Make every plausible argument for the truth of T. ("Underpinning.")

2) Criticize (find fault with) every argument for the truth of every rival theory. (“Undermining.")

3) Reply to every criticism of every argument for the truth of T. ("Countermining.")

4) Make every plausible argument for the falsity of every rival theory. ("Attacking.")

5) Criticize (find fault with) every argument for the falsity of T. ("Repelling.")

Suppose I wish to provide a complete defense of thesis T. I have three tasks:

1) Make every plausible argument for the truth of T. ("Underpinning.")

2) Reply to every criticism of every argument for the truth of T. ("Countermining.")

3) Criticize (find fault with) every argument for the falsity of T. ("Repelling.")

Why (it will be asked) are there only three tasks, rather than five? What happened to undermining and attacking? The answer is that undermining and attacking are offensive maneuvers. Their object is not to defend (protect) one's theory, but to destroy rival theories. In the case of a thesis, there are no rivals. There is only the contradictory (negation, denial) of the thesis, $\mathrm{T}$, which may be represented as $\sim \mathrm{T}$.

Suppose I set out to undermine $\sim \mathrm{T}$. To undermine $\sim \mathrm{T}$ is (by definition) to criticize (find fault with) every argument for the truth of $\sim \mathrm{T}$. Criticizing (finding fault with) every argument for the truth of $\sim \mathrm{T}$ is logically equivalent to criticizing (finding fault with) every argument for the falsity of $\mathrm{T}$. But that is precisely what repelling amounts to. Since repelling is already on the list of three tasks, undermining the contradictory of one's thesis is otiose.

Suppose I set out to attack $\sim \mathrm{T}$. To attack $\sim \mathrm{T}$ is (by definition) to make every plausible argument for the falsity of $\sim \mathrm{T}$. Making every plausible argument for the falsity of $\sim T$ is logically equivalent to making every plausible argument for the truth of T. But that is precisely what underpinning amounts to. Since underpinning is already on the list of three tasks, attacking the contradictory of one's 
thesis is otiose.

To make the discussion concrete, let the proposition "God exists" be our thesis. A complete defense of this thesis requires that I perform the following tasks:

1) Make every plausible argument for the truth of "God exists."

2) Reply to every criticism of every argument for the truth of "God exists."

3) Criticize (find fault with) every argument for the falsity of "God exists."

I perform task 1 by making arguments such as the Ontological Argument, the Cosmological Argument, the Teleological Argument, and the Moral Argument. I perform task 2 by replying to criticisms of these arguments. I perform task 3 by criticizing (finding fault with) arguments such as the Argument from Evil. 